\title{
Broad-band direct QPSK modulator/demodulator for wireless gigabit communication
}

\author{
CAO YuXiong ${ }^{1,2}$, WU DanYu ${ }^{1,2}$, LIU XinYu ${ }^{1,2^{*}} \& \mathrm{JIN}_{\mathrm{Zhi}}{ }^{1,2^{*}}$ \\ ${ }^{1}$ Institute of Microelectronics, Chinese Academy of Sciences, Beijing 100029, China; \\ ${ }^{2}$ Key Laboratory of Microelectronics Devices \& Integrated Technology, Institute of Microelectronics, Chinese Academy of Sciences, Beijing \\ 100029, China
}

Received July 2, 2012; accepted August 8, 2012

\begin{abstract}
The design and measured results of a broad-band direct quadrature phase shift keying (QPSK) modulator and demodulator are described in this paper. The circuits are fabricated using 1- $\mu \mathrm{m}$ GaAs HBT technology. To suppress the local oscillator $(L O)$ leakage, the double-balanced mixer is selected as the core unit in the modulator/demodulator. An embedded four-way quadrature divider which includes a Lange coupler and two Baluns is utilized in the system to generate quadrature-phase $L O$ signals. As results of a back-to-back test, the system can operate at data rates in excess of $2 \mathrm{~Gb} / \mathrm{s}(1 \mathrm{~Gb} / \mathrm{s}$ per $I$ and $Q$ channels $)$ at $30 \mathrm{GHz}$. The supplies of the modulator and demodulator are $5.0 \mathrm{~V}$ and $4.5 \mathrm{~V}$ with size of $1.35 \mathrm{~mm} \times 3.5 \mathrm{~mm}$ and $1.36 \mathrm{~mm} \times 3.4 \mathrm{~mm}$, respectively.
\end{abstract}

HBT, direct conversion, modulator, demodulator, QPSK, gigabit communication

Citation: Cao Y X, Wu D Y, Liu X Y, et al. Broad-band direct QPSK modulator/demodulator for wireless gigabit communication. Chin Sci Bull, 2013, 58: 427-432, doi: 10.1007/s11434-012-5566-4

The growing data communication speed, bandwidth limitation and congestions at lower frequencies have resulted in the move toward high frequency system. Wireless systems at Ka-band frequencies have various applications such as in point-to-point, point-to-multipoint, and very small aperture terminal (VSAT) systems. One of the most promising wireless communications service is the Local Multipoint Communication Service (LMCS). Additionally, there is a great demand on the Ka-band phased-array radar for military and commercial applications, which includes communications, navigation, weather forecast and so on. To meet the market demands, many researchers have developed highly monolithic microwave integrated circuits (MMICs) design and compact chip size for the high speed system applications $[1,2]$.

Direct conversion architecture (DCA) greatly reduces front-end hardware complexity, lower cost and no image frequency comparing to heterodyne technique [3-5]. There-

*Corresponding authors (email: xyliu@ime.ac.cn; jinzhi@ime.ac.cn) fore, passive reflection-type demodulator and modulator have been reported in various process [6-8] for millimeterwave (MMW) direct conversion systems, even gigabit data rate. However, the local oscillator $(L O)$ leakage and image suppression in these transceivers need be carefully considered. Because the $L O$ signal and $R F$ signal are connected in the same device. In addition, the baseband signals of the refection-type modulators need be calibrated, which will limit its applications.

The Ka-band has several features that render it ideal for high-data-rate radio links. The wide bandwidth available permits high speed transmission by utilizing a simple modulation scheme such as quadrature phase-shift keying (QPSK). Most importantly, antennas with high gain and directivity are easily realizable in this frequency range with apertures less than $2.3 f_{\mathrm{t}}$ [9]. However, in the compact chip die the passive components need be carefully considered to ensure broad-band phase and amplitude balance of the IQ signals.

This paper presents a broad-band modulator and demodulator using 1- $\mu \mathrm{m}$ GaAs HBT technology for direct conversion 
transceiver system. The proposed modulation scheme is direct QPSK. The double-balanced type mixers are selected to suppress the $L O$ leakage and improve the linearity. To minimize the phase and amplitude imbalance of the differential signals of the $L O$ and $R F$ ports, a coplanar waveguide (CPW) to coplanar-stripe (CPS) compact coupled $180^{\circ}$ balun is adopted to achieve a broad-band performance [10]. In addition, an MMW $90^{\circ}$ Lange coupler [11] and power combiner has been implemented in the HBT process to provide equal amplitude and quadrature-phases signals for the modulator and demodulator. The architecture can reduce the cost and power consumption due to these passive components. Finally, the experimental results show the HBT modulator and demodulator MMICs feature good direct conversion quality up to the gigabit data rate.

\section{Circuit design}

In order to simplify the transceiver architecture and to reduce the overall system power dissipation, a simple modulation scheme such as direct QPSK was selected in this work. The block diagram of the direct conversion transceiver system is illustrated in Figure 1. The baseband signals ( $I$ and $Q$ signals) are modulated by the up conversion mixer with the $L O$ carrier, and combined to the output signal $R F_{\text {out }}$. Then, the $R F_{\text {out }}$ as the input of the demodulator is translated into four quadrature signals $(I-, I+, Q-, Q+)$ by the demodulator.

The modulator and demodulator are fabricated in $1-\mu \mathrm{m}$ GaAs HBT technology. This process provides metal-insulatormetal (MIM) capacitors with $\mathrm{SiN}$ as dielectric and two metal layers for inter-connection. The HBT technology provides an $f_{\mathrm{t}}$ of $58 \mathrm{GHz}$ and $f_{\max }$ of $60 \mathrm{GHz}$ at maximum beta bias. The circuits are simulated with Agilent's Advanced Design System (ADS). The passive components including the baluns, Lange coupler, capacitors and connection-lines are simulated by a full-wave electromagnetic (EM) simulator (momentum) [12]. Finally, the passive components co-simulate with the active device modeling in the schematic workplace for the performance of the MMICs.

\subsection{Passive quadrature divider}

The passive components include baluns, Lange coupler and Wilkinson power combiner/splitter. One Lange coupler and two baluns compose the phase-shifting network, which plays an important role in the generation of equal amplitude and quadrature-phase $L O$ signals for the mixer. The combination network including two baluns and one Wilkinson power combiner combines four signals into one signal.

Baluns are key components in balanced circuit topologies such as double-balanced mixers, push-pull amplifiers and phase shifters. As the frequency of the circuits operation is extended to microwave band, transformer hybrids and LC

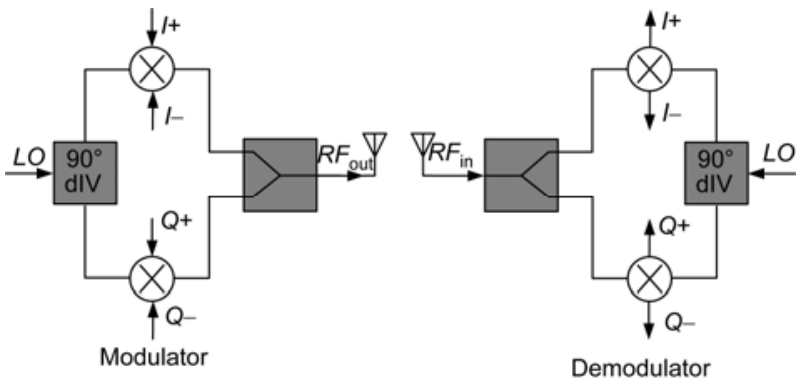

Figure 1 Block diagram of direct conversion modulator and demodulator.

type balun can no longer be fabricated, and the microstrip Marchand-type balun is utilized. In this design, multi-layer compact coupled structures will be adopted for broad-band performance [10]. The unbalanced input is fed through a 50 $\Omega$ CPW line and the balanced output is taken through a balanced CPS output lines. It is constructed with two strip lines using metal 1 and metal 2 . To obtain the appropriate coupling, the metal 2 is narrower than metal 1 . The line width of metal 1 is $50 \mu \mathrm{m}$ and metal 2 is $3 \mu \mathrm{m}$.

The other important passive components are $90^{\circ}$ Lange coupler and power combiner/splitter, which are designed automation by the EDA tools (ADS software). The $90^{\circ}$ Lange coupler, $180^{\circ}$ balun and the line connection are calculated using the full-wave EM simulator (ADS momentum) [11].

\subsection{Broad-band direct conversion QPSK modulator}

The Gilbert cell can be used as binary phase-shift keying (BPSK) modulator, which has two phase states $\left(0^{\circ}\right.$ and $\left.180^{\circ}\right)$ with the same amplitude. The QPSK modulators can be extended by two BPSK modulators, driven in quadrature by the $L O$ signal. By combining the two BPSK modulators in voltage at Wilkinson power combiner, a QPSK modulator is formed. The QPSK modulator is illustrated in Figure 2. The $L O$ signal is divided into four-way quadrature signals by the Lange coupler and baluns, which are mixed by the Gilbert cell. The mixed signals are combined into modulated signal by the baluns and Wilkinson power combiner/splitter.

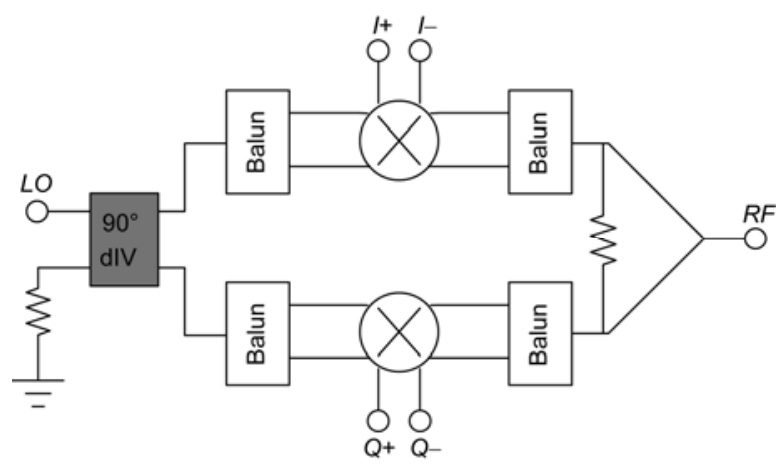

Figure 2 Block diagram of the HBT QPSK modulator. 
The double-balanced Gilbert cell was chosen due to its high linearity and high carrier suppression, which is shown in Figure 3. The bias of the intermediate frequency $(I F)$ data is supported by a current mirror. The constant current source is reduced and the differential $R F$ input transistors serve dual role: one in establishing the DC operating current and the other as the $R F$ switching portion of the mixer [10]. However, this will come at the expense of increasing the common-mode gain. Therefore, the emitter degenerating resistors $\left(R_{\mathrm{E}}=25 \Omega\right)$ are used in the $R F$ stage to improve the linearity of the $R F$ differential pair. In addition, it needs to design the accurate balun to minimize the imbalance of phase and amplitude for the $L O$ and $R F$ signals.

The DC bias is fed to the differential $L O$ signal pair through the balun and the $L O$ quad transistors are biased at $3 \mathrm{~mA}$. The direct QPSK modulator consumes $37 \mathrm{~mA}$ from $5 \mathrm{~V}$ power supply.

\subsection{Broad-band direct conversion QPSK demodulator}

The QPSK demodulator has the same block diagram and passive components with the modulator. The schematic of the direct down conversion Gilbert-cell is shown in Figure 4. An emitter-buffer for baseband active matching is integrated in the demodulator. The $L O$ and $R F$ signals are mixed to produce baseband signal in the Gilbert-cell, which is amplified by the output buffer. In addition, the emitter degenerating resistor $\left(R_{\mathrm{E}}=14 \Omega\right)$ is used in the $R F$ stage to improve the linearity of the differential pair and stability of the mixer.

The $R F$ and $L O$ signal are biased through baluns. The current sources of the output buffer are biased in a current mirror configuration. The demodulator consumes $70 \mathrm{~mA}$ current from $4.5 \mathrm{~V}$ power supply.

\section{Measurement results}

The phototgraphs of the QPSK modulator and demodulator are shown in Figures 5 and 6. Die size of the modulator and demodulator are $1.35 \mathrm{~mm} \times 3.5 \mathrm{~mm}$ and $1.36 \mathrm{~mm} \times 3.4$ $\mathrm{mm}$, respectively. The supplies of the modulator and demodulator are 5.0 and $4.5 \mathrm{~V}$, respectively. These chipsets are packaged on the evaluation boards for measurements, which includes baseband balun and power supply bias.

\subsection{The QPSK modulator characteristics}

The measured equipments of the QPSK modulator consist of baseband IQ source (Agilent E8267D), arbitrary waveform generator (Agilent 81134A), LO source (Agilent N5183), spectrum analyzer (Agilent E4440A) and vector signal analyzer (Agilent 93204A oscilloscope). The setup of the measurement system is shown in Figure 7.

The modulator is evaluated by a QPSK modulation with data rate of $36 \mathrm{Ms} / \mathrm{s}$ at $25 \mathrm{GHz} L O$ signal. The measured output spectrum of the modulator is illustrated in Figure 8, which demonstrated an adjacent channel power ratio (ACPR) of $-37 \mathrm{dBc}$.

For vector signal characterization, the analog $32 \mathrm{GHz}$ bandwidth oscilloscope Agilent 93204A is used for the QPSK modulator measurement. Figure 9 illustrates the measured output spectrum for an $L O$ signal at $25 \mathrm{GHz}$ with

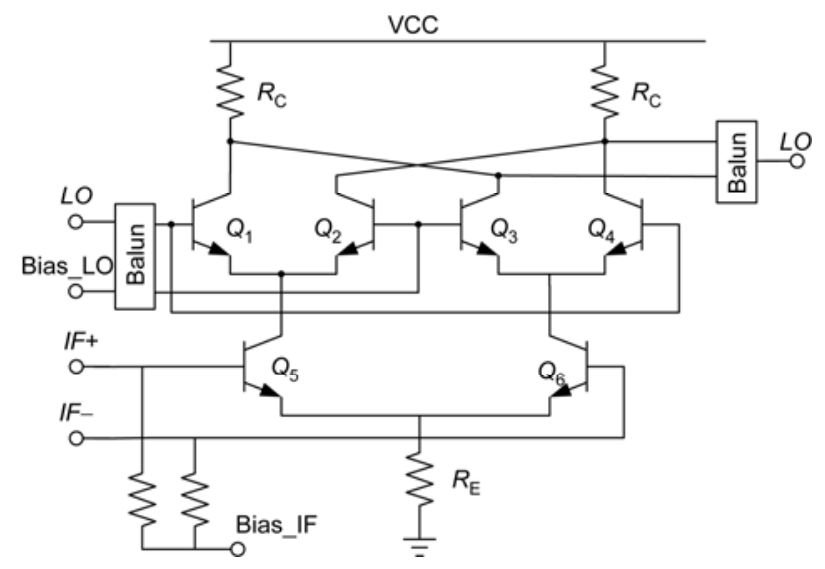

Figure 3 Schematic of the Gilbert cell for the QPSK modulator.

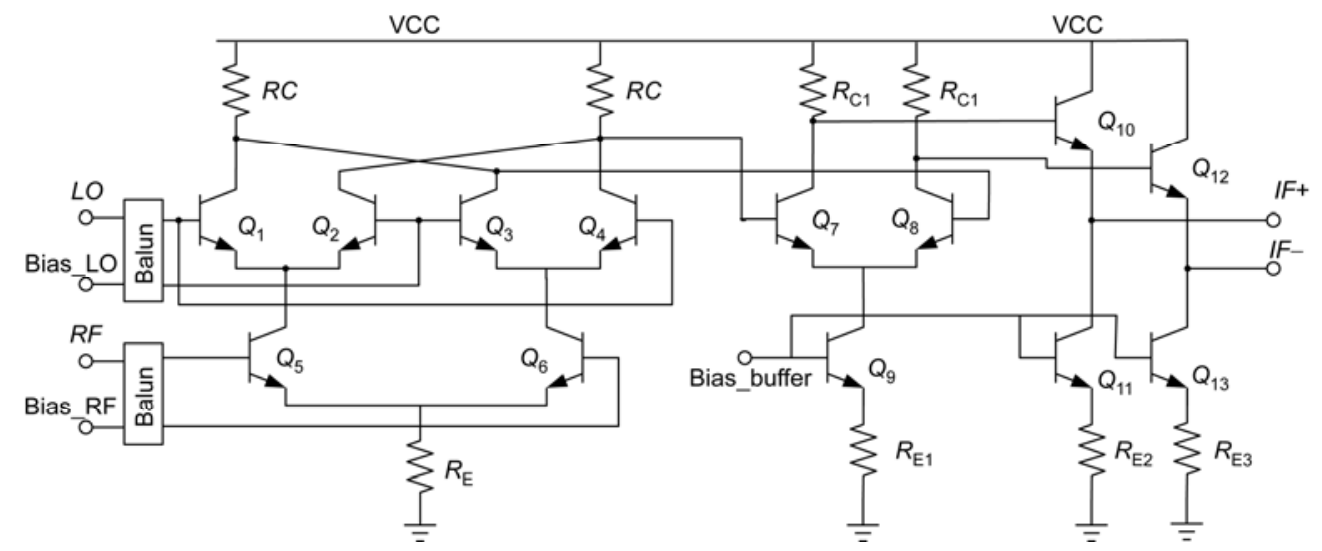

Figure 4 Schematic of double-balanced direct downconversion Gilbert-cell. 


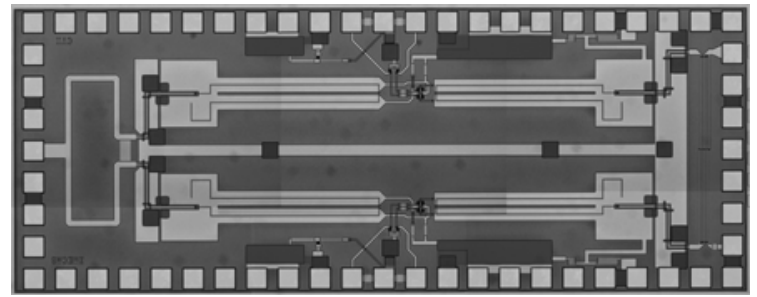

Figure 5 Die photography of the QPSK modulator with chip size of $1.35 \mathrm{~mm}$ $\times 3.5 \mathrm{~mm}$.

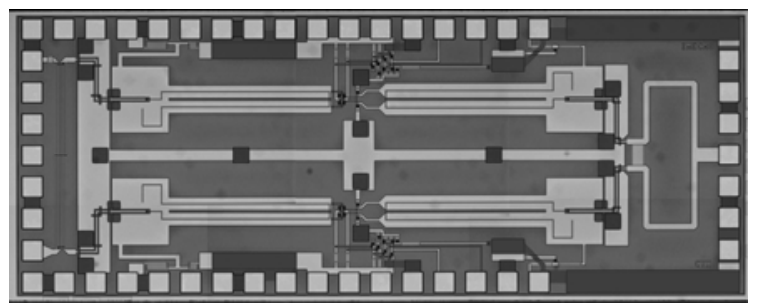

Figure 6 Die phototgraphy of the QPSK demodulator with chip size of $1.36 \mathrm{~mm} \times 3.4 \mathrm{~mm}$

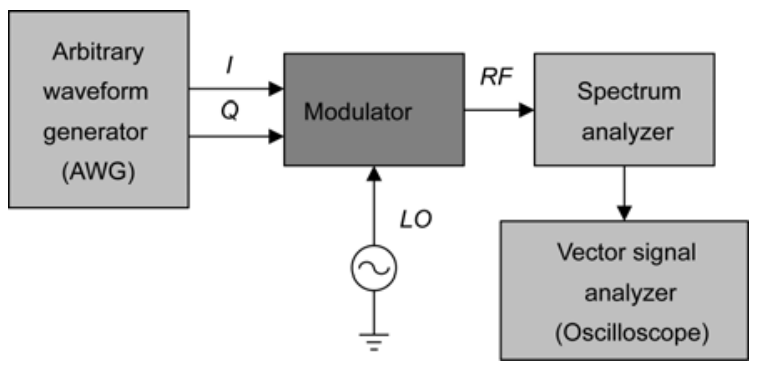

Figure 7 Block diagram of the MMW vector measurement system for the modulator.

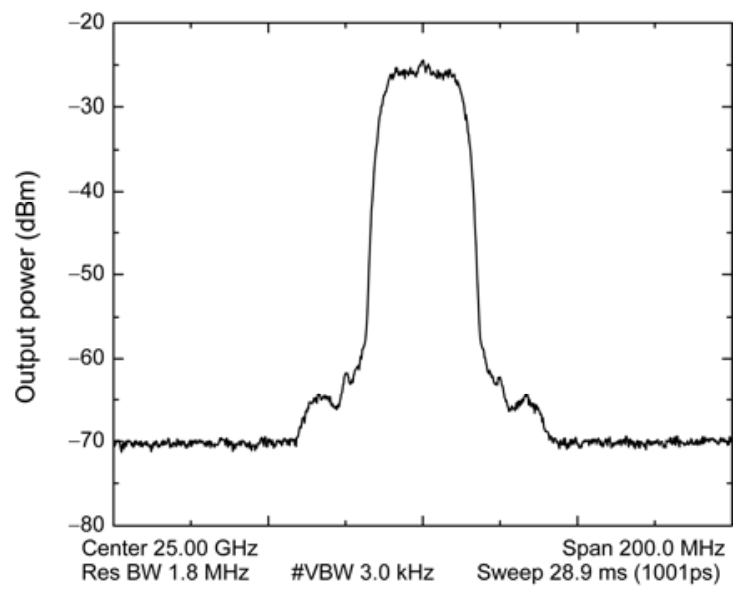

Figure 8 Measured output spectrum of the QPSK modulator at $25 \mathrm{GHz}$ with $36 \mathrm{Ms} / \mathrm{s}$ QPSK modulation with ACPR $-37 \mathrm{dBc}$.

a QPSK data rate of $1 \mathrm{~Gb} / \mathrm{s}$ pseudorandom bit stream (PRBS) per $I$ and $Q$ channels. The points in the QPSK constellation can be spread out uniformly into a "square". The measured error vector magnitude (EVM) of the QPSK

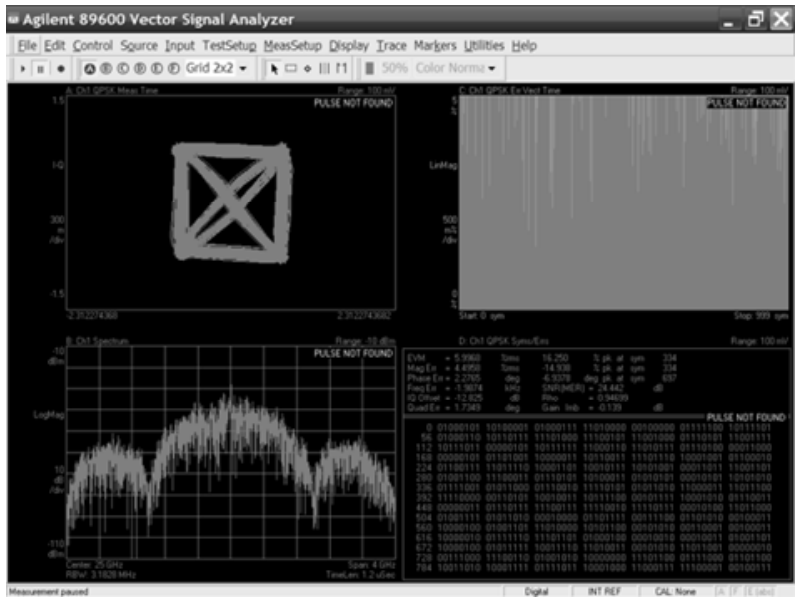

Figure 9 Measured QPSK modulation results at $25 \mathrm{GHz}$, constellation diagram, output spectrum and performance summary.

modulation is within 6\%. The lobes of the QPSK spectrum are visible at this bit rates, which has good $L O$ suppression.

\subsection{The QPSK demodulator characteristics}

The phase and amplitude imbalance for the QPSK demodulator are important performance. Two signal sources (Agilent N5183 and Agilent E8267D) are used to measure thus imbalance. An oscilloscope is used to observe the $I+, I-, Q+$ and $Q$ - time-domain waveforms. Figure 10 reproduces the waveforms at the four baseband outputs versus time corresponding to an $L O$ of $20 \mathrm{GHz}$. The slight amplitude and phase imbalance observed among the four outputs.

\subsection{The QPSK demodulator characteristics}

The modulator and demodulator are performed a back-toback test. An attenuator is inserted between the modulator and demodulator. The measurements setup is shown in

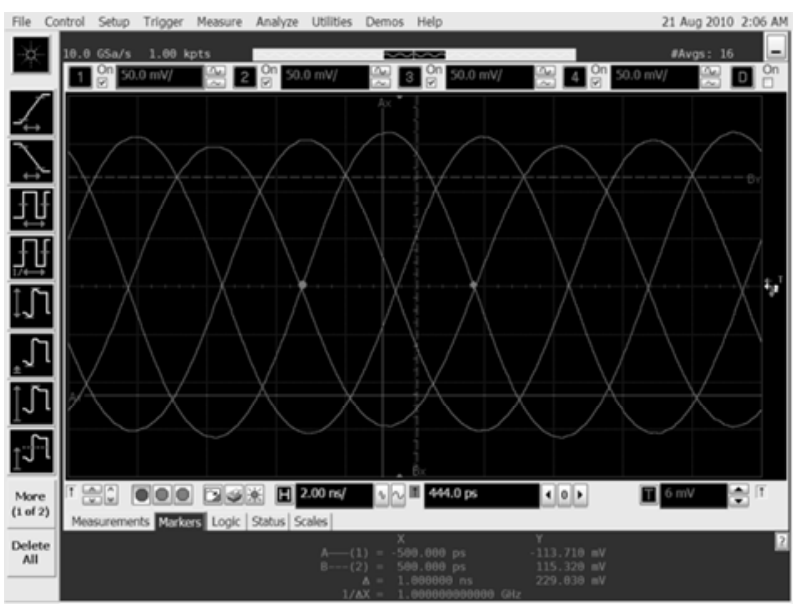

Figure $10 I+, I-, Q+$ and $Q-I F$ outputs versus time when $f_{\mathrm{LO}}=20 \mathrm{GHz}$ and $f_{\mathrm{IF}}=10 \mathrm{MHz}$. 
Figure 11. The data generator Agilent 81134A and the oscilloscope Agilent 93204A are used here to measure the bit stream. The $L O$ signal of the system adopt one frequency source at $30 \mathrm{GHz}$. Figure 12 shows the eye diagram at the $I$ and $Q$ outputs of the receiver at $2 \mathrm{~Gb} / \mathrm{s}(1 \mathrm{~Gb} / \mathrm{s}$ per channel) bit rate with PRBS sequences. The eye diagram of the $I$ and $Q$ have no phase calibration at $1 \mathrm{~Gb} / \mathrm{s}$ bit rate due to no variable phase shifter between the $L O$ signal and demodulator. To be observed, the clear eye opening is achieved for the satisfactory recovery of the baseband signals.

Table 1 is the performance summary of previously reported modulators and demodulators in various technologies and topologies. Compared to reported modulators and demodulators, our presented chips demonstrates small chip sizes using GaAs HBT process and high data-rate up to 2 $\mathrm{Gb} / \mathrm{s}$.

\section{Conclusion}

The $20 \mathrm{GHz}$ to $30 \mathrm{GHz}$ QPSK modulator and demodulator using 1- $\mu \mathrm{m}$ GaAs HBT technology for wireless gigabit applications has been presented in this paper. The chipsets are suitable for broad-band digital QPSK modulations due to their wide bandwidth, low EVM degradation and good ACPR performance. Therefore, the modulator and demodulator can be used in the high speed communications at $\mathrm{Ka}$ band. It is shown that in back-to-back configuration, the modulator and demodulator can operate in excess of $2 \mathrm{~Gb} / \mathrm{s}$ at $30 \mathrm{GHz}$. Therefore, these chipsets provide a low-cost solution and broad-band applications for high data-rate signals.

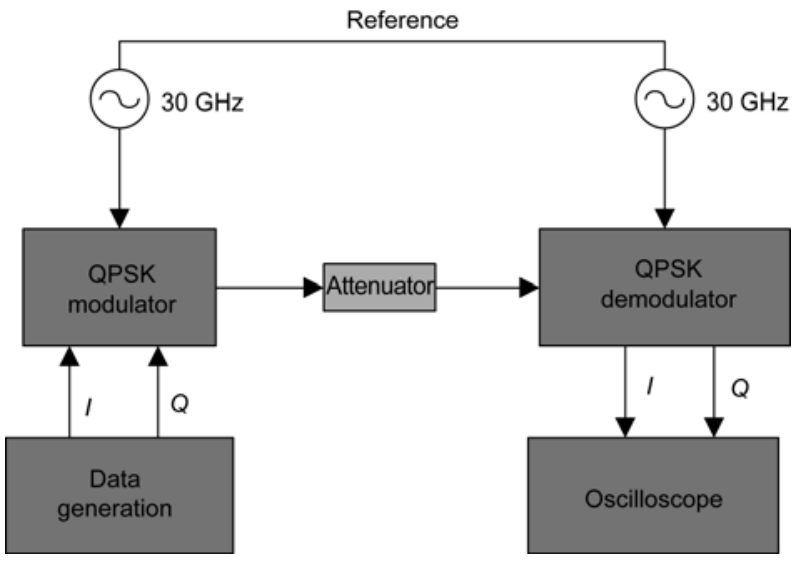

Figure 11 The measurement system setup for the modulator and demodulator test.

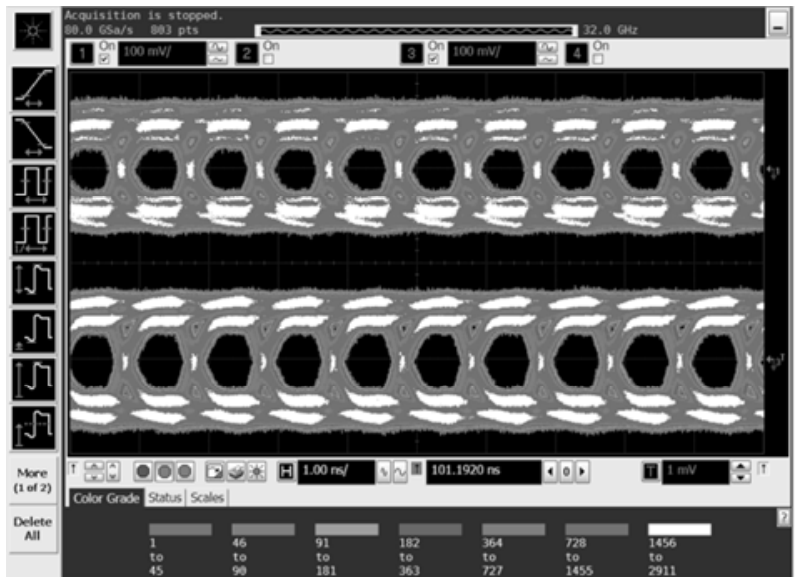

Figure 12 Measured eye diagram at both the $I$ and $Q$ outputs corresponding to $2 \mathrm{~Gb} / \mathrm{s}$ QPSK data tansmission ( $1 \mathrm{~Gb} / \mathrm{s}$ per $I$ and $Q$ channels).

Table 1 Comparisons of modulators and demodulators in various technologies and topologies

\begin{tabular}{|c|c|c|c|c|c|}
\hline Technology & $\begin{array}{c}0.13-\mu \mathrm{m} \\
\text { CMOS [6] }\end{array}$ & $\begin{array}{c}2-\mu \mathrm{m} \mathrm{GaAs} \\
\text { HBT [13] }\end{array}$ & $\begin{array}{c}2-\mu \mathrm{m} \mathrm{GaAs} \\
\mathrm{HBT}[14]\end{array}$ & $\begin{array}{c}2-\mu \mathrm{m} \mathrm{GaAs} \\
\mathrm{HBT}[15]\end{array}$ & $\begin{array}{c}1-\mu \mathrm{m} \mathrm{GaAs} \\
\text { HBT [This work] }\end{array}$ \\
\hline Module & Modulator & $\begin{array}{c}- \\
\text { /demodulator }\end{array}$ & $\begin{array}{c}\text { Modulator } \\
\text { /demodulator }\end{array}$ & $\begin{array}{c}\text { Modulator } \\
\text { /demodulator }\end{array}$ & $\begin{array}{c}\text { Modulator } \\
\text { /demodulator }\end{array}$ \\
\hline$L O$ frequency & $20-40 \mathrm{GHz}$ & $20-40 \mathrm{GHz}$ & $30-50 \mathrm{GHz}$ & $20-40 \mathrm{GHz}$ & $20-30 \mathrm{GHz}$ \\
\hline Topology & $\begin{array}{l}\text { Reflection- } \\
\text { type }\end{array}$ & $\begin{array}{l}\text { Double balanced Gil- } \\
\text { bert-cell }\end{array}$ & $\begin{array}{l}\text { Single balanced diode } \\
\text { mixer }\end{array}$ & $\begin{array}{l}\text { Reflection-type } \\
\text { /Gilbert-cell }\end{array}$ & $\begin{array}{l}\text { Double balanced } \\
\text { Gilbert-cell }\end{array}$ \\
\hline Data rate & $>1.0 \mathrm{~Gb} / \mathrm{s}$ & $1.0 \mathrm{~Gb} / \mathrm{s}$ & $2.0 \mathrm{~Gb} / \mathrm{s}$ & $2.0 \mathrm{~Gb} / \mathrm{s}$ & $>2.0 \mathrm{~Gb} / \mathrm{s}$ \\
\hline Modulation scheme & 64-QAM & QPSK & BPSK & QPSK & QPSK \\
\hline ACPR modulator & $\begin{array}{l}-40 \mathrm{dBc} \\
@ 30 \mathrm{GHz}\end{array}$ & - & -30 dBc@30-50 GHz & - & $\begin{array}{l}-37 \mathrm{dBc} \\
@ 25 \mathrm{GHz}\end{array}$ \\
\hline Power consumption & $\begin{array}{c}0 / \\
0\end{array}$ & $\begin{array}{c}981 \mathrm{~mW} / \\
-\end{array}$ & $\begin{array}{l}2.6 \mathrm{~mW} / \\
2.6 \mathrm{~mW}\end{array}$ & $\begin{array}{l}0 / \\
-\end{array}$ & $\begin{array}{l}185 \mathrm{~mW} / \\
315 \mathrm{~mW}\end{array}$ \\
\hline Chip size & $0.65 \mathrm{~mm} \times 0.58 \mathrm{~mm}$ & $3.0 \mathrm{~mm} \times 4.0 \mathrm{~mm}$ & $\begin{array}{l}1 \mathrm{~mm} \times 1 \mathrm{~mm} / \\
1 \mathrm{~mm} \times 1 \mathrm{~mm}\end{array}$ & $\begin{array}{l}3.3 \mathrm{~mm} \times 2.5 \mathrm{~mm} / \\
3.3 \mathrm{~mm} \times 4.5 \mathrm{~mm}\end{array}$ & $\begin{array}{l}1.35 \mathrm{~mm} \times 3.5 \mathrm{~mm} / \\
1.36 \mathrm{~mm} \times 3.4 \mathrm{~mm}\end{array}$ \\
\hline
\end{tabular}

This work was supported by the National Basic Research Program of China (2010CB327505). The authors thank LI YanKui and OUYAN SiHua for measurement guidance.
1 Jri L, Yenlin H, Yentso C, et al. A low-power fully integrated 60 $\mathrm{GHz}$ transceiver system with OOK modulation and on-board antenna assembly. In: IEEE International Solid-State Circuits Conference 
(ISSCC), 2009 8-12 Feb 2009, San Francisco, CA. 16-318

2 Mahon S J, Convert E, Beasly $\mathrm{P}$ T, et al. Broadband integrated millimeter-wave up- and down-converter GaAs MMICs. IEEE Trans Microwave Theory Tech, 2006, 54: 2050-2060

3 Ioannis S, Sean T N, Alexander T, et al. An 18-Gb/s, direct QPSK modulation SiGe BiCOMS transceiver for last mile links in the 70-80 GHz band. IEEE J Soild-State Circuits, 2010, 45: 1968-1980

4 Jeng $\mathrm{H} \mathrm{T}$, Tian W H. 35-65 GHz CMOS broadband modulator and demodulator with sub-harmonic pumping for MMW wireless gigabit applications. IEEE Trans Microwave Theory Tech, 2007, 55: 20752085

5 Tomkins A, Aroca R A, Yamamoto T, et al. A zero-IF $60 \mathrm{GHz} 65 \mathrm{~nm}$ CMOS transceiver with direct BPSK modulation demonstrating up to $6 \mathrm{~Gb} / \mathrm{s}$ data rates over a $2 \mathrm{~m}$ wireless link. IEEE J Solid-State Circuits, 2009, 44: 2085-2099

6 Hong Y C, Pei S W, Tian W H, et al. Design and analysis of CMOS broad-band compact high-linearity modulators for gigabit microwave/millimeter-wave applications. IEEE Trans Microwave Theory Tech, 2006, 54: 20-30

7 McPherson D S, Lucyszyn S. Vector modulator for W-band software radar techniques. IEEE Trans Microwave Theory Tech, 2001, 49: $1451-1461$
8 Chang H Y, Huang T W, Wang H. Broad-band HBT BPSK and IQ modulator MMICs and millimeter-wave vector signal characterization. IEEE Trans Microwave Theory Tech, 2004, 52: 908-919

9 Lockie D, Peck D. High-data-rate millimeter-wave radios. IEEE Microwave Mag, 2009, 10: 75-83

10 Hamed K W, Freundorfer A P, Antar Y M M, et al. A novel monolithic double balanced direct conversion mixer with an integrated broadband monolithic passive balun. IEEE J Solid-State Circuits, 2005, 40: 622-629

11 Lange J. Interdigitated stripline quadrature hybrid. IEEE Trans Microwave Theory Tech, 1969, 17: 1150-1151

12 Agilent ADS manual Version 2009U1, 2009

13 Hamed G K W, Freundorfer A P, Antar Y M M, et al. A high-bit rate Ka-band direct conversion QPSK demodulator. IEEE Microwave Wireless Compon Lett, 2008, 18: 365-367

14 Chang H Y, Weng S H, Chiong C C. A 30-50 GHz wide modulation bandwidth bidirectional BPSK demodulator/modulator with low LO power. IEEE Microwave Wireless Compon Lett, 2009, 19: 332-334

15 Freundorfer A P, Hamed K, Sun Y, et al. A direct digital $2 \mathrm{~Gb} / \mathrm{s}$ modulator/demodulator experiment in GaAs $\mathrm{HBT}$ at $30 \mathrm{GHz}$. In: Proc Asia-Pacific Microwave Conf, 2006 12-15 Dec 2006, Yokohama, Yokohama. 1611-1614

Open Access This article is distributed under the terms of the Creative Commons Attribution License which permits any use, distribution, and reproduction in any medium, provided the original author(s) and source are credited. 